\title{
Enforcement key to China's environment
}

On 1 January 2015, China formally began implementing its revised Environmental Protection Law (EPL). The new EPL offers some hope for sustainable development in China, but its potential may be limited if local governments continue to focus on the economy.

Since the first EPL in 1989, China has become the largest emitter of carbon dioxide (1). After many calls for its revision (2), the new EPL, which was finalized in April 2014 (3), includes substantial amendments (4). Caps on penalties have been lifted, the "per day calculation" for pollution fines should increase punishments, and some NGOs will be able to bring lawsuits against polluters. An ecological "red line" will define areas requiring special protection from, for example, urban smog.

The new EPL looks good on paper, but it remains to be seen how local environmental protection bureaus will use it. Local bureaus have often attempted to reconcile conflicting goals of economic development and environmental protection (5). The situation exacerbated by overlapping responsibilities of local governments and the Ministry of Environmental Protection. Environmental responsibilities scattered across different ministries and agencies further weaken EPL enforcement $(6)$.

Application of environmental laws in rural, less developed, areas has been much weaker than in cities (5). Because of protests by middle-class city dwellers, factories have relocated to rural middle and western China $(7,8)$, causing serious environmental degradation. This includes major water pollution within Inner Mongolia's deserts (9). Strengthening EPL enforcement in these areas is essential to avoid the spread of contamination.

The potential for environmental litigation is still limited. Only the largest NGOs will be able to initiate lawsuits, with only around 300 qualifying (10). Provisions for lawsuits against environmental enforcement authorities remain unclear.

The Chinese Premier has declared "war on pollution". The new EPL provides weapons for this war, but their effectiveness will depend on enforcement, particularly in China's developing regions.

\section{Hong Yang, ${ }^{1 *}$ Xianjin Huang, ${ }^{2 *}$ Julian R. Thompson, $^{3}$ Roger J. Flower ${ }^{3}$}

${ }^{1}$ CEES, Department of Biosciences, University of Oslo, Blindern, 0316, Oslo, Norway. ${ }^{2}$ School of Geographic and Oceanographic Science, Xianlin Campus, Nanjing University, Nanjing, 210023, China.

${ }^{3}$ Wetland Research Unit/Environmental Change Research Centre, UCL Department of Geography, University College London, London, WC1E 6BT, UK.

*Corresponding author. E-mail: hongyanghy@gmail.com (H. Y.); hxj369@nju.edu.cn (X. H.)

\section{References}

1. PBL Netherlands Environmental Assessment Agency, Trends in Global $\mathrm{CO}_{2}$ Emissions 2013 Report (2014); http://edgar.jrc.ec.europa.eu/news_docs/pbl-2013-trends-in-global-co2-emissions-2013-report-1148.pdf

2. G. Z. He, L. Zhang, A. P. J. Mol, Y. L. Lu, J. G. Liu, Science 341, 133 (2013).

3.H. Yang, Nature 509, 535 (2014).

4.The National People's Congress of the People's Republic of China, Environmental Protection Law of the People's Repulic of China (2014); www.npc.gov.cn/huiyi/lfzt/hjbhfxzaca/2014-04/25/content_1861320.htm [in Chinese].

5.G. Kostka, "Barriers to the implementation of environmental policies at the local level in China," World Bank Policy Research Working Paper (World Bank, Berlin, 2014).

6.J. G. Liu, W. Yang, Science 337, 649 (2012).

7.H. Yang, R. J. Flower, J. R. Thompson. Nature 490, 342 (2012).

8.H. Yang, X. Huang, J. R. Thompson, R. J. Flower, Science 344, 691 (2014).

9.S. Huan, Water pollution in N. China desert kills thousands of birds (2014); www.ecns.cn/cns-wire/2014/09-12/134208.shtml. 10. J. Y. Hsu, Geogr. Compass 8, 98 (2014). 